\title{
Effect of Sugarcane Bagasse Fiber on Geopolymer Concrete when it is Subjected to Alternative Drying and Wetting
}

\author{
T. Srinivas ${ }^{1}$, Pogula Anudeep ${ }^{2}$, N. V. Ramana Rao ${ }^{3}$ \\ ${ }^{1}$ Professor, GRIET, Hyderabad, India. \\ ${ }^{2}$ P.G. Student, GRIET, Hyderabad, India. \\ ${ }^{3}$ Professor, JNTUH, Hyderabad, India.
}

\begin{abstract}
Various types of fibers like glass, steel, coconut fiber, sugarcane bagasse fiber, etc are used to increase the mechanical properties of the concrete. SCBF is the final residue of the sugar industries which is used in this study. The objective of the paper is to study the effect of SCBF in geopolymer concrete (GPC) and conventional concrete (CC) of equivalent grade of M40 when it is subjected to alternative drying and wetting. The specimens are treated with water by alternative wetting and drying process. This test consists of periodic cycles, each cycle consists of one wetting day and drying day. The specimens are tested for the compressive strengths after 7, 14 and 28 cycles. The compressive strength of the CCF and GPCF are higher than the CC and GPC respectively and the optimum compressive strengths are obtained at $0.5 \%$ of fiber dosage. The \% loss of compressive strength and \% loss of weights of CCF and GPCF are calculated and compared with the CC and GPC. From the results obtained, the strength loss and the weight loss in the CCF and GPCF are less when compared to the CC and GPC when treated in alternative wetting and drying process.
\end{abstract}

\section{Introduction}

Ordinary Portland Cement (OPC) is widely used in the construction of the concrete structures. Whereas the production of cement needs large amount of raw materials. The production processes of cement are also emitting large amount of carbon-di-oxide, which one of the green house gasses. Thus, the cement industries are impacting on the global environment. The high strength concrete is developed by trials, with different mix proportion. To reduce this effect on the environment, eco-friendly concrete is developed and it is termed as the geopolymer concrete (GPC) by replacing the cement by the cementitious materials like Fly ash and GGBS by the usage of alkali-activators like alumina and silicates.

The mechanical properties of the GPC are higher than the CC of same grade. This GPC is early strength, light in weight,highly resistant to fire and also resists to water at different conditions. The mechanical properties such as compressive strength bond strengths are higher than CC. Since the GPC is the denser concrete it is more durable then the $\mathrm{CC}$ of same grade. ${ }^{*}$ The workability of the concrete is the mainly considered characteristics. The workability of the GPC is slightly less when compared to its equivalent concrete M40, but still in the range. The compressive strengths in the GPC are higher than the $\mathrm{CC}$ of similar grade.

\footnotetext{
* Corresponding author : srinu.tummala@gmail.com
}

Concretes are high in the compressive strength but weak in the tensile strength. To improve this tensile strength in the concrete material, various types of fibers are introduced with different thickness and lengths. The ratio between the length of fiber to its thickness is termed as the Aspect Ratio. And the natural fibers like (palm fiber, coconut fiber, jute fiber, sisal fiber, sugarcane fiber) and synthetic fiber like (steel fiber, glass fiber, polypropylene fiber, etc) are used.By the addition of fibers in the concrete, the concrete gets denser, which leads to the development in the durable properties in the concrete. By the addition of the fibers in the concrete the workability of the concrete is further reduced and it is in the limits. But there is an increase in the mechanical properties like compressive strength and tensile strength in the concrete by introducing the fiber with certain percentage. Workability of the concrete can be achieved by the addition of Super plasticizer to the concrete mix, this super plasticizer does not affect the mechanical properties of the concrete.

Natural fibers are the bi-products of the agricultural industries. Sugarcane Bagasse is the final residue of the sugar industry. India occupied $2^{\text {nd }}$ position in the cultivation of the sugarcane in the world.So, the sugarcane bagasse is cheaply available when compared to the other fibers. This sugarcane bagasse consists of fiber and small amount of water particles. Geopolymer concrete with SCBF (GPCF) and conventional concrete 
with SCBF (CCF)are produced higher results when compared to the GPC and CC respectively.

The main objective of this paper to study the effect of SCBF in the concrete mix of both CC and GPC and compare its results when the concrete specimens are treated with water by alternative wetting and drying processes. This Alternative Wetting and Drying test are conducted through the period of 28 cycles. Each cycle consists of one wetting day (fully immersed in the water for 24 hours) and one drying day (removed from water and dried in sun for 24 hours). The " $\%$ Loss of Compressive Strength" and the "\% Loss of Weight" of CCF and GPCF are calculated and compared with the $\mathrm{CC}$ and GPC.

\section{Materials}

\subsection{Ordinary Portland Cement}

OPC of 53-grade was used in this experiment. Specific gravity of the cement is 3.15 . And it is in the limits specified in IS 12629-1987.

\subsection{Fine Aggregate}

River sand which is passed through IS sieve $475 \mathrm{~mm}$ and having the specific gravity as $2.67,2.8 \%$ as its water absorption and belongs to zone-II according to IS: 383 1970 was used.

\subsection{Coarse Aggregate}

The crushed granites of maximum size of $20 \mathrm{~mm}$ angular shaped is used as the coarse aggregate.And the specific gravity of the coarse aggregate is 2.6 .

\subsection{Fly Ash}

For this experiment, fly ash is collected from the RMC plant in Bollaram,

\subsection{Ground Granulated Blast Furnace Slag}

GGBS is a byproduct of the steel industry. Here $25 \%$ of the binders are replaced with GGBS.

\subsection{Water}

Waterwhich is free from chemicals, oils and other impurities is used in the concrete mix as perIS:456:2000.

\subsection{Sodium Hydroxide}

Sodium hydroxide is used to activate the binding property (flyash and GGBFS) in the mix designs of the GPC. The mix design of GPC is directly affected by changing the molar concentration of the $\mathrm{NaOH}$. Sodiumhydroxide is mostly in the form of pelletsandthismaterialisboughtfromthelocal laboratory chemical vendors in Hyderabad.Sodium Hydroxide is one of the major ingredients of geopolymer concrete. Sodium Hydroxide is one of the major ingredients of geopolymer concrete. Table 1 shows the specificationsof the sodium hydroxide asgiven bythesuppliers

Table 1. Shows Physical properties of $\mathrm{NaOH}$.

\begin{tabular}{|c|c|}
\hline Molar mass & $40 \mathrm{gm} / \mathrm{mol}$ \\
\hline Appearance & White solid \\
\hline Density & $2.1 \mathrm{gr} / \mathrm{cc}$ \\
\hline Melting point & $318 \mathrm{Oc}$ \\
\hline Boiling point & $1390 \mathrm{Oc}$ \\
\hline $\begin{array}{r}\text { Amount of heatliberated when } \\
\text { dissolved inwater }\end{array}$ & $267 \mathrm{cal} / \mathrm{gram}$ \\
\hline
\end{tabular}

\subsection{Sodium Silicate Solution}

Sodium silicate solution plays an important in the polymerization in the GPC. It is a type of alkaline liquid. $\mathrm{NaOHis}$ procured fromlocal chemical vendors in Hyderabad.Table 1 shows the specifications of the sodium Silicate solution asgiven by thesuppliers

Table 2. Properties of $\mathrm{Na} 2 \mathrm{SiO} 3$ Solution

\begin{tabular}{|c|c|}
\hline Specific gravity & 1.57 \\
\hline Molar mass & $122.06 \mathrm{gm} / \mathrm{mol}$ \\
\hline $\mathrm{Na}_{2} \mathrm{O}$ (by mass) & $14.35 \%$ \\
\hline $\mathrm{SiO}_{2}$ (by mass) & $30.00 \%$ \\
\hline Water (by mass) & $55.00 \%$ \\
\hline $\begin{array}{c}\text { Weight ratio (SiO } \\
\mathrm{Na}_{2} \mathrm{O} \text { ) }\end{array}$ & 2.09 \\
\hline Molarity ratio & 0.97 \\
\hline
\end{tabular}

\subsection{Super Plasticizer}

Sulfonated Naphthalene Formaldehyde (SNF)is added to improve the serviceability of concrete. In this study superplasticizer utilized was $2 \%$ of binder.

\section{Experimental Investigation}

\subsection{General}

An objective of this paper is to study the compressive strength and alternative wetting and drying properties of geopolymer concrete of grade G40, wheresugarcane bagasse fiberand also to compare the results of geopolymer concrete made with sugarcane bagasse fiberwith geopolymer concrete and controlled concrete of respective grade. The size of cubes was cast has $100 \mathrm{~mm} \times 100 \mathrm{~mm} \times 100 \mathrm{~mm}$ and after 24 hours rest period, the specimens were cured for a period of 24hours at $60^{\circ} \mathrm{C}$ in oven and the rest of the period cured under the ambient curing.

\subsection{Mixing and Casting of Geopolymer Concrete}

Geopolymerconcrete by using the same materials that are used for controlled concrete by a similarprocedure. By using the pan mixer in the laboratory, the fine 
aggregate, coarse aggregate, fly ash and GGBS are mixed for 2 minutes, thenthe alkaline liquid is mixed with the superplasticizer and additional water if needed and added to the mix. And the mixture proceeded for 2 more minutes. Slump test is used to measure the workability of the concrete.

\subsection{Compressive Strengths}

From the studies made it was noted that the compressive strength increases with the increase in the age of the concrete. It was also noted that, with an increase inmolarity of the sodium hydroxide solution there was increase in the compressive strength of concrete. Thecompressive strengths are influencedby the ratio of flyash to alkaline liquid. As the ratio increases, then the compressivestrengths of GPC also increased buthere in this experiment the ratio and the temperature are kept constant. When low water content isused in the geopolymer mixes, the alkaline activatorconcentration tends to increase in the system. Thus, the available high alkalinitycould accelerate the geo polymerization process, and increasethe concrete's final strength. Aspect ratio of the fiber also differs the compressive strengths of the concrete. aspect ratio is the ratio between the thickness of the fiber to its length (aspect ratio= thickness of the fiber/length of the fiber). From the literature, it is noted that the considerable aspect ratio of the fiber is up to 75 . The graph linear upto an aspect ratio of 75 , later graph slopes down. Further increase in the aspect ratio leads to the decrease in the compressive strength. And also depending up on the percentage of the fiber added to the concrete, compressive strengths differs. In this project we compared the geopolymer concrete made with the sugarcane bagasse fiber at different percentages like $0.25 \%, 0.5 \%, 0.75 \%$, $1.0 \%$.Optimum strength is obtained at $0.5 \%$ of fiber with the aspect ratio of 66.7

Table 3. Compressive Strengths of CCF and GPCF with Different $\%$ of Fiber

\begin{tabular}{|r|r|r|r|}
\hline \multicolumn{1}{|l|}{ Trial } & \% of fiber & \multicolumn{1}{l|}{ CCF } & \multicolumn{1}{l|}{ GPCF } \\
\hline 1 & 0 & 49.20 & 50.51 \\
\hline 2 & 0.25 & 52.45 & 52.75 \\
\hline 3 & $\mathbf{0 . 5}$ & $\mathbf{5 5 . 3 0}$ & $\mathbf{5 6 . 8 0}$ \\
\hline 4 & 0.75 & 53.06 & 54.25 \\
\hline 5 & 1 & 50.75 & 51.41 \\
\hline
\end{tabular}

\subsection{Alternative Wetting and Drying}

GPC of grade 40 is made with sugarcane bagasse fiber is used. The objective of this test to identify the effect of sugarcane bagasse fiber in the concrete, with alternative wetting and drying process. In this test the specimens are treated with water and dried with regular cycles. Where one cycle takes two days (48 hours), one day dried in the atmospheric temperature and next day completely immersed in the water. And the difference in weights are calculated and at the same time the strength loss is identified by the compressive test. And these values are compared with the controlled concrete and the plane GPC and also with the CC made with the same dosage of sugarcane bagasse fibers.

Table 4. Loss of CompressiveStrengthwhen Subjected to Alternative Wetting and Drying

\begin{tabular}{|c|c|c|c|c|}
\hline Cycles & 0 & 7 & 14 & 28 \\
\hline $\mathrm{CC}$ & 49.23 & 46.53 & 44.53 & 43.86 \\
\hline $\begin{array}{l}\text { \% loss of } \\
\text { compressive } \\
\text { strength }\end{array}$ & - & 5.48 & 9.5 & 10.89 \\
\hline $\mathrm{CCF}$ & 55.30 & 52.41 & 50.26 & 49.65 \\
\hline $\begin{array}{l}\% \text { loss of } \\
\text { compressive } \\
\text { strength }\end{array}$ & - & 5.21 & 9.1 & 10.2 \\
\hline GPC & 50.52 & 48.17 & 46.16 & 45.51 \\
\hline $\begin{array}{l}\% \text { loss of } \\
\text { compressive } \\
\text { strength }\end{array}$ & - & 4.65 & 8.62 & 9.9 \\
\hline GPCF & 56.80 & 54.23 & 52.13 & 51.40 \\
\hline $\begin{array}{l}\% \text { loss of } \\
\text { compressive } \\
\text { strength }\end{array}$ & - & 4.51 & 8.21 & 9.5 \\
\hline
\end{tabular}

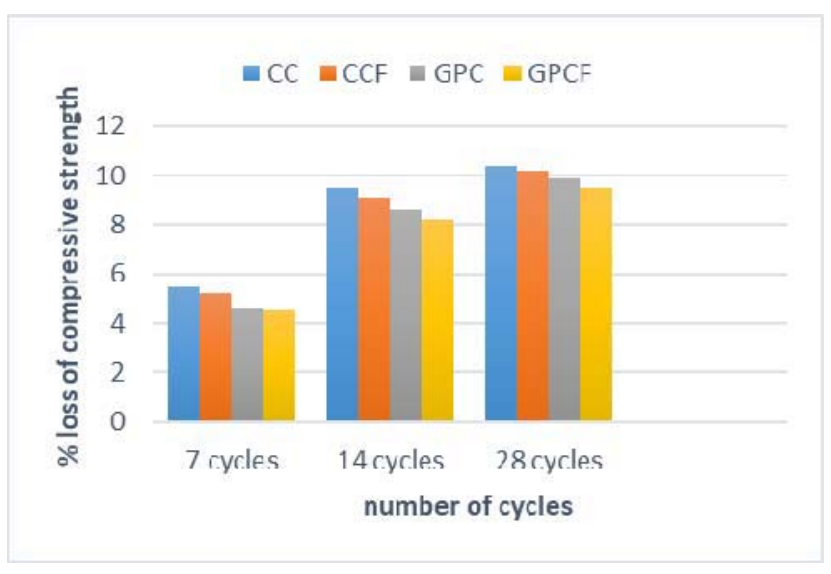

Fig. 1. Shows \% Loss of Compressive Strength with Alternative Wetting and Drying

Table 5. Loss of Weight when Subjected to Alternative Wetting and Drying

\begin{tabular}{|l|l|l|l|l|}
\hline Cycles & 0 & & 7 & \multicolumn{1}{|l|}{28} \\
\hline CC & 2.512 & 2.508 & 2.498 & 2.487 \\
\hline \% loss of weight & - & 0.159 & 0.557 & 0.995 \\
\hline CCF & 2.520 & 2.517 & 2.508 & 2.498 \\
\hline$\%$ loss of weight & - & 0.119 & 0.476 & 0.873 \\
\hline
\end{tabular}




\begin{tabular}{|l|l|l|l|l|} 
& 2.316 & 2.313 & 2.306 & 2.296 \\
\hline \% loss of weight & - & 0.129 & 0.431 & 0.863 \\
\hline GPCF & 2.303 & 2.301 & 2.295 & 2.285 \\
\hline \% loss of weight & - & 0.086 & 0.347 & 0.781 \\
\hline
\end{tabular}

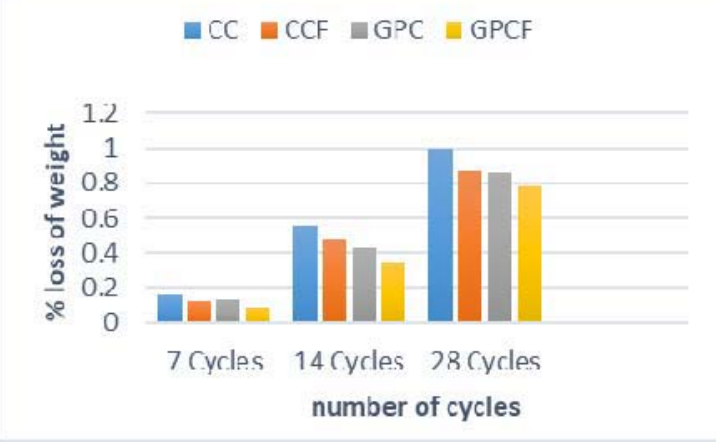

Fig. 2. Shows \% Loss of Weight with Alternative Wetting and Drying

\section{Conclusion}

1 It is observed that the workability of CC and GPC are reduced with the addition of SCBF, but still in the required limits.

2 The compressive strengths of the CCF and GPCF are higher than the $\mathrm{CC}$ and GPC.

3 It states that compressive strength of the concrete is optimum at $0.5 \%$ dosage of sugarcane bagasse fiber (SCBF) in both CCF and GPCF. It is observed that further increase in the dosage of SCBF reduces the strength of the concrete.

4 The compressive strength losses of CCF and GPCF are reduced by $6.33 \%$ and $4.04 \%$ respectively when compared to CC and GPC under alternative wetting and drying processes for 28 cycles.

5 The loss of weights of CCF and GPCF are decreased by $7.21 \%$ and $5.88 \%$ respectively when compared to the $\mathrm{CC}$ and GPC under alternative wetting and drying processes for 28 cycles.

6 By the addition of sugarcane bagasse fiber (SCBF) there is a reduction in the \% loss of compressive strengths and \% loss of weight in CC and GPC when subjected to alternative wetting and drying process.

\section{References}

1. Henry A Colorado, John F Zapata, J. Mater. Environ. Sci, 10, 1162-1171 (2019)

2. Tanveer Singh Bains, Khushpreet Singh, IJITEE, 8, 7, (2019)

3. T. Srinivas, P. Manoj Anand, IJITEE, 8, 12, (2019)

4. Ankur Laxman Yadav, V. Sairam, K. Srinivasan, L. Muruganandam, Const. and Buil. Mater., 258, 119231 (2020)

5. Srinivas Rao J, S K Tummala, Kuthuri N R, Indonesia Journal of Electrical Engg. \& Computer Science, 21 (723), 2020
6. Ankur Laxman Yadav, V. Sairam, L. Muruganandam, K. Srinivasan, Jour. of Cle. Prod, 245,118854, (2020)

7. Francisco Hernandez-Olivares, Rosa Elizabeth Medina-Alvarado, Xavier Eduardo BurneoValdivieso, Alonso Rodrigo Zuniga-Suarez, Const. and Buil. Mate, 247, 118451 (2020)

8. Zuzhong Li, Xuelei Zhang, Chunguang Fa, Yayun Zhang, Jianping Xiong, Huaxin Chen, Const. and Buil. Mate, 248, 118648, (2020)

9. Arslan Akbar, Furqan Farooq, Muhammad Shafique, Fahid Aslam, Rayed Alyousef, Hisham AbdulJabbar, Jour. of Buil. Engi, 33, 101492 (2021)

10. T.Srinivas and M. Abinay Raj, Int. J. of Eng.and Adv. Tech. (IJEAT), ISSN: 2249 - 8958, Volume-8 Issue-6 (2019)

11. T.srinivas and P. Manoj Anand, Int. J. of Innov. Tech. and Explor. Eng.g (IJITEE), ISSN: 22783075, Volume-8 Issue-12 (2019)

12. T.Srinivas and G. Sukesh Reddy, Int. J. of Eng.and Adv. Tech. (IJEAT), ISSN: 2249 - 8958, Volume-9 Issue-1 (2019)

13. T.Srinivas and R. N. Koushik, Int. J. of Innov. Tech. and Explor. Eng.g (IJITEE), ISSN: 22783075, Volume-8 Issue-12 (2019), PP 112-117.

14. Prashant Singh B.T., Babu Bobba Phaneendra and K. Suresh , E3S Web Conf., 87 (2019) 01010

15. K. Sai Gopi, Dr. T. Srinivas and S. P. Raju V, E3S Web of Conferences ICMED 184, 01084GRIET, 28-29

February, https://doi.org/10.1051/e3sconf/2020184011084(20 20)

16. Jagannadha Kumar, M.V., Jagannadha Rao, K., Dean Kumar, B., Srinivasa Reddy, V., Int. J. of Civil Eng. and Tech., 9(7), pp. 1133-1141 (2018)

17. Ganta, J.K., Seshagiri Rao, M.V., Mousavi, S.S., Srinivasa Reddy, V., Bhojaraju, C., Structures 28, pp. 956-972 (2020)

18. Naidu, K.S.S.T., Rao, M.V.S., Reddy, V.S., Int. J. of Innov. Tech. and Explor. Eng.g (IJITEE), 8(9 Special Issue 2), pp. 641-642 (2019)

19. Chandana Priya, C., Seshagiri Rao, M.V., Srinivasa Reddy, V., Int. J. of Civil Eng. and Tech., 9(11), pp. 2218-2225 (2018)

20. B. T. P. Singh, B. P. Babu and Y. Satyavani, 2019 IEEE Transportation Electrification Conference (ITEC-India), 2019, pp. 1-6

21. Satya Sai Trimurty Naidu, K., Seshagiri Rao, M.V., Srinivasa Reddy, V., Int. J. of Civil Eng. and Tech., 9(11), pp. 2383-2393 (2018)

22. A.U. Haq, A. K. Kavit, T. Rao, T. Buddi, D. Baloji, K. Satyanarayana, S. K. Singh, Materials Today: Proceedings, 18, 4589 (2019)

23. Supriya, Y., Srinivasa Reddy, V., Seshagiri Rao, M.V., Shrihari, S., Int. J. of Rec. Tech. and Engi., 8(3), pp. 5381-5385 (2019)

24. Kotkunde, N., Krishna, G., Shenoy, S.K., Gupta, A.K., Singh, S.K. International Journal of Material Forming, 10 (2), pp. 255-266 (2017)

25. Govardhan, D., Kumar, A.C.S., Murti, K.G.K., Madhusudhan Reddy, G. Materials and Design, 36, 
pp. 206-214. (2012)

26. Kumar, P., Singhal, A., Mehta, S., Mittal, A. Journal of Real-Time Image Processing, 11 (1), pp. 93-109. (2016)

27. Raghunadha Reddy, T., Vishnu Vardhan, B., Vijayapal Reddy, P. International Journal of Applied Engineering Research, 11 (5), pp. 30923102 (2016)

28. Hussaini, S.M., Krishna, G., Gupta, A.K., Singh, S.K. Journal of Manufacturing Processes, 18, pp. 151-158 (2015) 